\title{
Integrating emotions into fine-grained accounts of students' reasoning
}

\author{
Ayush Gupta \\ Department of Physics, University of Maryland, College Park, MD 20742.
}

\begin{abstract}
Many prominent lines of research on students' reasoning and conceptual change within learning sciences and physics education research have not attended to the role of learners' affect or emotions in the dynamics of their conceptual reasoning. This is despite evidence that emotions are deeply integrated with cognition and documented associations between emotions and academic performance. I present the case for research aimed at integrating emotions with models of learners' cognition. I present a case-study to argue that, in physics learning environments, learners' emotions can be intertwined with the unfolding conceptual and epistemological reasoning at fine time-scales. This case-study draws on video-taped interactions of a small group of students working on a physics tutorial. The analysis of the conceptual and epistemological substance of students' talk and the associated emotions draws on a combination of methodologies from knowledge analysis, interaction analysis, and conversation analysis traditions. I end with implications for research and instruction.
\end{abstract}

Keywords: physics education, affective variables, utterances PACS: 01.40.Fk

\section{INTRODUCTION}

As an instructor, I have noticed emotions strongly influencing students' conceptual and epistemological engagement in my classroom. In particular, I have noticed individual and contextual variations: one student's confusion gives way to anxiety leading to further errors, while another student's conceptuallysimilar confusion evokes curiosity and resolve, leading to progress. My desire to understand such phenomena motivates this research.

Research indicates that emotions strongly influence performance on a variety of cognitive tasks. [1-6] But many influential accounts of learning in science, especially in the 1980s and 1990s, have focused only on learners' conceptual reasoning,[711] in spite of calls for greater attention to students' affect. [12-14] Within research on physics learning, the focus has largely been on the content of students' ideas, problem-solving skills, epistemologies, and instructional strategies. [15-20]

Researchers, however, have started attending to learners' emotions. [21-29] I highlight two particular results: the correlation of emotions with achievement and the correlation of emotions with epistemological beliefs. Using survey questions to probe emotions, Pekrun et al. show that hopelessness and boredom are negatively correlated to achievement as measured by tests and grades. [21] Craig et al. monitor students' emotions during a learning intervention, and using summary measures of different emotions over many students they show a strong correlation between "confusion" and learning gains measured by pre-post testing. [23] Eynde et al. follow variations in learners' emotions over short time scales to show that emotions correlate with learners' epistemological beliefs and self-efficacy measured using surveys. [28] Bodin and Winberg found that students' performance on a classical mechanics assignment was associated with expert-like epistemologies (such as sensemaking) and emotions associated with control and concentration, with beliefs and emotions being measured by self-reports on survey instruments. [27]

While these studies illustrate that emotions influence learning and beliefs about learning, they don't show how emotions couple to learning in the moment (with very few exceptions [26,29]). Also missing are explanations of contextual variations within individuals.

Investigating the conceptual and epistemological substance of students' talk and associated emotionson a moment-to-moment basis-can complement past studies by characterizing such variations and shedding light on how emotions sustain or destabilize reasoning patterns in particular instances. [30] The fine-grained integration of emotions with conceptual and epistemological stances aims at an understanding of students' learning experiences as inextricably rational-cognitive and emotional. 


\section{METHODS}

The setting for the data: The data presented here come from a classroom episode where three students - "Alan," "Kendra," and "Jasmine" (pseudonyms) were discussing a Newton's Third Law question on their physics tutorial worksheet. This data has been analyzed differently elsewhere. [31,32]

Methodologically, my analysis borrows from techniques of both cognitive analysis $[8,33]$ and interaction analysis, [34] helping to forge pathways for integrating perspectives that have largely remained divergent so far. While not engaging in systematic interaction analysis, I informally borrow tools from conversation and interaction analysis to attend to embodied participation (gestures, facial expressions, body posture), para-verbal features of talk (pitch, intonation contours, register), word choice, the sequential organization of talk and action, trouble and repair in conversation, spatial and temporal organization of activity, and the material features of the setting. For analyzing emotions, I relied on these interactional features as well as the content of utterances.[35,36] Analysis of the conceptual and epistemological content of the talk draws on the knowledge-in-pieces framework, which models knowledge as loosely organized abstractions. $[8,33]$ This ontology of conceptual and epistemological knowledge is particularly suited to analyze the fine-timescale dynamics of knowledge.

\section{CASE STUDY ANALYSIS}

The tutorial opens with asking students to compare the forces exerted on a truck and a car when the moving truck collides with the stationary car, half its mass, first by relying on their intuitions and then by using Newton's Third Law. In this initial few minutes Alan, Jasmine, and Kendra are mostly working on the question by themselves, checking in briefly with one another on their answers. They agree that intuitively the truck will exert a bigger force on the car and that Newton's Law says that the forces are equal. But while their answers are contradictory, their manner of engagement in this initial phase indicates that they are not attending to this mismatch (their tones are flat, their gaze on their own papers, and they express neither surprise nor confusion). Then Kendra speaks up:

Kendra: i $\uparrow$ kị:nda- $\underline{i}$ could never understa: tha:t bu:t (2.3) cuz $\uparrow \underline{i}$ mean- does=this- $\underline{\text { does }}=$ this go agai:nst um the la:w the:n?, or is=it that $(0.5)$ they a::re equal we just think it's the tru:ck. (0.5) $>$ you understand what my question-<
\{Transcript follows Jefferson's conventions [37]: number in parenthesis implies duration of pause in seconds; colon (:) implies extended vowel utterance; underlined text implies emphasis (pitch or volume); punctuation indicates intonation; square brackets [ ] mark the start and end of overlapping talk; = implies continuation without pause; $\uparrow$ and $\downarrow$ indicate sharp changes in pitch; capitalization implies increased volume; talk within $><$ is at a faster pace.

Kendra's remark marks a departure from previous utterances and behaviors - a clear, strong tone, shift in gaze from worksheet to group members, shift in body posture from hunched over to sitting up. Affectively, Kendra's behaviors reflect greater arousal and give voice to her confusion about the incongruence in this situation between intuition and Newton's Third Law. Epistemologically, Kendra is making a bid to discuss "[her] question," seeking reconciliation between intuition and Newton's Third Law. And it opens up the space for analyzing that physical situation: in response to Kendra's question, Alan and Jasmine take the position that their intuition results from the perceived relative motion of the car and truck, while the law accurately describes the forces on the vehicles; and that the tutorial will help them resolve this soon. The students go back to writing on their worksheets without reaching a resolution. Moments later, a tutorial instructor (TA) checks in and Kendra tries to clarify their confusion:

Kendra: Does- (0.4) newton's=law have to do with ah spe:ed or anythị:ng, $\downarrow_{\text {or }}$ is it jus::t

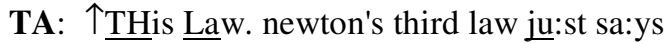
that the forces on the two are equalal.

Kendra: it doesnt ma::tter what the spe:::ed doesnt matter about anything else, the si:ze-

TA: > we are gonna look at tha:t.< so tho::se are go:od questi:ons.

Kendra's question hints at a possible path to resolution that she might be considering, focusing on the distinction between speed and force. (The TA restates Newton's third law but defers the resolution of Kendra's paradox.) Kendra's effort, so far, to resolve the mismatch between her intuition and the law reflects an underlying epistemological stance that such a reconciliation is possible and desirable.

After the TA leaves, the students resume their discussion. Kendra actively engages with Alan and Jasmine bringing up an incident of personal experience when she was in an accident and the smaller car was much more damaged than the bigger car. A few minutes later, the TA conducts a class demonstration aimed at showing that in a collision between two objects of different masses the forces on the objects are the same; but due to a malfunctioning force probe, the results are erroneous. The demonstration leaves Kendra more confused and 
frustrated. The group then moves on to the next question, which prompts an explicit epistemological discussion on the role of intuition in understanding physics. Here, Alan and Jasmine pick the option that reconciliation between physics and intuition is usually possible, using the warrant that their professor explicitly assumed this stance. Kendra, however, rejects that option. Asked why by Alan, she

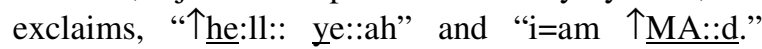
Kendra's negative emotions here are evident in the tone and loudness as well as the content of her utterance. The utterance also reflects her rejection of the possibility of reconciling her intuition with Newton's Third Law. The single utterance thus carries both emotional and epistemological meaning. Her irritation is clear in the exchange that follows:

Alan: there's alwa:ys some way to explain

Kendra: you thi:nk so::?

Jasmine: yeah.

Alan: yeah.

Kendra: $\uparrow \underline{I}$ dont think there's any way that you can expla:in to me ho::w, a ma::ssive truck=

Kendra: $=$ [is going to ha:ve the same forces on it. $\underline{i}$ just have to accept $\underline{i t}$.]

Jasmine: [i think they do: fee:el the sa:me force its ju:st one is $\underline{\mathrm{i}}:: \mathrm{ke]}$ (1.2)

Kendra: I dont $\uparrow \underline{\mathrm{SEE}}:$ : it.

Kendra's stance here that a reconciliation with common sense is impossible, that she has to just "accept" Newton's third law without further explanation, stands in sharp relief to her efforts in the earlier episode to resolve the common-sense/physics mismatch.

Kendra's response, however, marks the frustration generated at failed attempts to reconcile her intuition and formal knowledge. Kendra's response also provides opportunity for further conceptual discussion. Alan and Jasmine respond to Kendra by offering that unseen damage to the truck chassis might make it plausible that the forces are equal. But now, Kendra resists all attempts at reconciliation. The episode ends with Kendra unconvinced and Alan and Jasmine taking the stance that the tutorial will probably help them resolve this later.

So far, I have shown the coordinated crescendo of Kendra's affect and her growing rejection of the possibility of conceptual reconciliation. The next episodes provide further evidence that her affect influenced her epistemological stance and conceptual reasoning.

The tutorial next asks students to apply the "car reacts more" intuition to determine the change in the car's speed relative to the change in the truck's speed. The question is designed to elicit the correct intuitive idea that, during the collision, since the car is half as heavy, it speeds up by twice as much as the truck slows down. Guided calculations then help students see that this correct intuition implies that the truck and car indeed exert equal forces upon one another.

If Kendra is driven by her first stance - seeking reconciliation - she should be positively engaged in this part of the tutorial, which guides students toward the first step of such a reconciliation. By contrast, if her stance rejecting the possibility of reconciliation is stable, then the intervention showing that the forces are numerically equal should not engage her much, since she already accepts that the forces are equal.

However, finishing that calculation elicits an entirely different reaction: Alan and Jasmine express enthusiasm and joy:

Jasmine: oh $\uparrow$ wow look=ho: w cool tha:t is

Alan: ye:ah. that makes sense. tha::ts re::ally cool.

Kendra, on the other hand, expresses discomfort:

\section{Kendra:}

$\underline{\mathrm{OH}} \underline{\mathrm{my}}$ goo::dness. ge:t the he::ll out of here, thats sca::ry to me.

Kendra is excited but also seems uncomfortable. A few minutes later, talking to one of the TAs, Kendra challenges the intervention as "mathematical" and making sense only "on paper."

To explain this outcome, I argue that Kendra's emotions "infused" her reasoning [3], that her negative emotion drew from and sharpened her meaningful discomfort with the ideas. That discomfort is productive; as Goel and Vartanian recently argued, such negative emotions can sharpen logical judgment of the validity of inferences. [6] By this account, Kendra's negative affect disposed her to critically examine the intervention, leading to the (sensible!) conclusion that the intervention offered only numerical proof, not an intuitive reconciliation.

For additional evidence that Kendra's epistemological stance toward physics/intuition reconciliation is coupled to her emotions, I look to the end of the tutorial hour, when students are prompted to reflect on the "car reacts more" intuition. By this time, the anger and frustration apparent in the earlier segments seem to have subsided. Here, Kendra actively engages with Alan in reconciling physics and intuition, associating the "car reacts more" intuition with changes in velocity - the same reconciliation pathway (posed by the tutorial) that she had rejected a few minutes ago!

Through the tutorial, Kendra's emotions and reasoning are coordinated at fine timescales (at times evidenced in single utterances): when calm, she worked to reconcile the physics-intuition divide; when angry, she rejected the possibility of such reconciliations. This, along with the success of Forgas' affect-infusion construct in explaining her 
reaction to the tutorial intervention, strongly suggests that Kendra's affect is not just epiphenomenal; it is central to the shifts and stabilities in her epistemological stances and associated conceptual reasoning.

\section{CONCLUSION}

Kendra's case illustrates that developing casestudy accounts and models that dynamically couple emotional states with fine-grained conceptual and epistemological stances can provide causal accounts of the fine-timescale shifts and stabilities in both affect and cognition. Insight into the role of affect in students' reasoning can expand the toolbox of theoretically-grounded instructional diagnoses, practices, and innovations that might be more effective than those based on "cold" cognitive analysis ${ }^{12}$. Research and instructional design that attends to learners' emotions can take us another step closer to a whole person view of the learner.

This work also raises further questions. Given that emotions influence learners conceptual reasoning and performance, how should we interpret students' performance on instruments such as the Force Concept Inventory or Maryland Physics Expectations survey? Also needed is further refinement and validation of the nature of relationship between learners' emotions, conceptions, and epistemologies through more case studies as well as large-N experiments.

\section{ACKNOWLEDGEMENTS}

For discussions that helped develop the ideas presented in this paper, I thank Andrew Elby, David Hammer, members of the Affect Gang (Luke Conlin, Lama Jaber, Jayson Nissen, Jennifer Richards, Vashti Sawtelle, Chandra Turpen, and Jessica Watkins), and members of the University of Maryland Physics Education Research Group.

\section{REFERENCES}

${ }^{1}$ D. A. Norman, Cogn. Sci. 4, 1-32 (1980).

${ }^{2}$ A. Damasio, Descartes' Error: Emotion, Reason, and the Human Brain (Penguin (Non-Classics), 2005).

${ }^{3}$ J. P. Forgas, Psychol. Bull. 117, 39-66 (1995).

${ }^{4}$ P. B. Carr and C. M. Steele, J. Exp. Soc. Psychol. 45, 853-859 (2009).

${ }^{5}$ J. E. LeDoux, Annu. Rev. Neurosci. 23, 155-184 (2000).

${ }^{6}$ V. Goel and O. Vartanian, Cogn. Emot. (2010).

${ }^{7}$ S. Vosniadou, Learn. Instr. 4, 45-69 (1994).
${ }^{8}$ A. A. diSessa, Cogn. Instr. 10, 105-225 (1993).

${ }^{9}$ A. A. diSessa and B. L. Sherin, Int. J. Sci. Educ. 20, 1155 (1998).

${ }^{10}$ S. Carey, Am. Psychol. 41, 1123-30 (1986).

${ }^{11}$ M. T. H. Chi, J. D. Slotta, and N. De Leeuw, Learn. Instr. 4, 27-43 (1994).

${ }^{12}$ P. R. Pintrich, R. W. Marx, and R. A. Boyle, Rev. Educ. Res. 63, 167-199 (1993).

${ }^{13}$ D. B McLeod and V. M Adams, Affect and Mathematical Problem Solving: A New Perspective (Springer Verlag, 1989).

${ }^{14}$ R. Duit and D. F. Treagust, Int. J. Sci. Educ. 25, 671 (2003).

${ }^{15}$ L. C. McDermott and E. F. Redish, Am. J. Phys. 67, 755 (1999).

${ }^{16}$ L. C. McDermott, Am. J. Phys. 69, 1127 (2001).

${ }^{17}$ E. F Redish, Am. J. Phys. 67, 562 (1999).

${ }^{18}$ F. Reif, Am. J. Phys. 63, 17-32 (1995).

${ }^{19}$ L. Hsu, E. Brewe, T. M Foster, and K. A Harper, Am. J. Phys. 72, 1147 (2004).

${ }^{20}$ I. A. Halloun and D. Hestenes, Am. J. Phys. 53, 1056-1065 (1985).

${ }^{21}$ R. Pekrun, T. Goetz, W. Titz, and R. P. Perry, Educ. Psychol. 37, 91 (2002).

${ }^{22}$ M. Gregoire, Educ. Psychol. Rev. 15, 147-179 (2003).

${ }^{23}$ S. D. Craig, A. C. Graesser, J. Sullins, and B. Gholson, J. Educ. Media 29, 241-250 (2004).

${ }^{24}$ S. D'Mello, R. W. Picard, and A. Graesser, IEEE Intell. Syst. 22, 53-61 (2007).

${ }^{25}$ D. K. Meyer and J. C. Turner, Educ. Psychol. Rev. 18, 377-390 (2006).

${ }^{26}$ R. Nemirovsky, J. Learn. Sci. 20, 308-337 (2011).

${ }^{27}$ M. Bodin and M. Winberg, Phys. Rev. Spec. Top. Phys. Educ. Res. 8, 010108 (2012).

${ }^{28}$ P. Eynde, E. Corte, and L. Verschaffel, Educ. Stud. Math. 63, 193-207 (2006).

${ }^{29}$ K. Weber, Res. Math. Educ. 10, 71-85 (2008).

${ }^{30}$ A. Gupta, B. A. Danielak, and A. Elby, arXiv:1307.1333 (2013).

${ }^{31}$ R. E. Scherr and D. Hammer, Cogn. Instr. 27, 147 (2009).

${ }^{32}$ L. D. Conlin, Building Shared Understandings in Introductory Physics Tutorials Through Risk, Repair, Conflict \& Comedy, 2012.

${ }^{33}$ D. Hammer and A. Elby, in Pers. Epistem.

Psychol. Beliefs Knowl. Knowing, edited by B. K. Hofer and P. R. Pintrich (L. Erlbaum Associates., Mahwah, N.J, 2002), pp. 169-190.

${ }^{34}$ B. Jordan and A. Henderson, J. Learn. Sci. 4, 39103 (1995).

${ }^{35}$ M.H. Goodwin and C. Goodwin, Commun. Arena Dev. 33-53 (2000).

${ }^{36}$ C. Goodwin, Discourse Soc. 18, 53 (2007).

${ }^{37}$ G. Jefferson, Pragmat. New Ser. 125, 13-34 (2004). 